\title{
A Risk-Based Model For Retirement Planning
}

Raida Abuizam, Purdue University Calumet, USA

\begin{abstract}
This paper presents the use of @ RISK simulation to estimate the value of a long-term investment in a diversified portfolio along with the risk associated with that investment. A number of possible investment scenarios in fixed income and equity securities are presented. Each simulation considers a possible set of portfolio weights for combinations of the different securities. The initial constraint is that the sum of the investment weights is equal to one. The simulation model creates future scenarios by randomly choosing past scenarios, giving higher probability weights to more recent years. The estimated future value of the investment is deflated to determine the amount in today's dollars. Finally, for each portfolio scenario, the model determines the value at risk VAR, which captures the maximum possible expected portfolio value.
\end{abstract}

Keywords: Investment Strategy, Simulation, Retirement Planning

\section{INTRODUCTION}

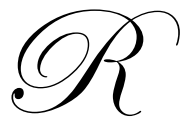

etirement planning is becoming a very hot topic. With advances in medical technology and population increases, planning for the future is more important than ever. The baby boom generation-those 77 million Americans born during postwar period of 1946 and 1964-has witnessed the Dow Jones Industrial Average increase by a factor of 40 and has also enjoyed approximately 500 percent growth in home equity during their adult lives. However, despite these increases, 25 million of the 77 million boomers currently have a net worth of less than $\$ 1,000$, excluding the value of their home equity (Levine, 2005). Indeed, when the baby boomers' financial situations are taken in conjunction with rising life expectancies, it is clear that baby boomers will require high-quality retirement planning advice.

The goal for retirees is to have an amount of money at retirement that will support the desired level of spending for their expected life, plus some number of years as a buffer. Retirees also would like to have some level of confidence that the retirement plan will hold up under practical assumptions about possibly undesirable investment results.

Money Tree, U.S News, Fidelity, Vanguard, Financial Engines, and NETirement are examples of companies that offer Internet-based simulations to help retirees. For retirees who are unfamiliar with mathematical simulations, or even the Internet itself, the process may well be regarded as a "black box" out of which flows investment advice. With the plethora of choices presented, retirees would likely be overwhelmed as to which ones are best for them.

The good news is that a generally accepted approach, often referred to as Monte Carlo and @RISK simulation by Palisade, anticipates the probability of meeting specific financial goals at certain times in the future. @RISK uses advanced Monte Carlo simulation techniques to analyze risk in any spreadsheet model. This is accomplished by generating thousands of possible scenarios the retiree's investment might take during the years until he or she is ready to retire. Analysts can find out not only what could happen, but how likely it is to happen. These scenarios can be used to answer important questions by the investor, such as "What is the chance that I will meet my retirement goals?" or' "What is the reasonable downside to the investment strategy that I am using?" 
To create these different scenarios, sets of financial statistics are combined over and over in new ways that are consistent with what we know about the financial markets. The simulation model is based on creating future scenarios by randomly selecting past scenarios, giving higher probability weights to more recent years. Finally, the estimated future value of the investment is deflated to determine the amount in today's dollars. The model also applies the value at risk VAR method by examining probabilities of failing to achieve various target portfolio values. In this study, VAR is the $5^{\text {th }}$ percentile of the underlying distribution. It therefore provides the threshold below which lies the worst case scenario.

\section{LITRATURE REVIEW}

Recent interests in retirement planning have resulted in a growing number of studies that examine the survivability of retirement portfolios in relationship to asset allocations. Elton and Gruber (1975) use dynamic programming to analyze multi period portfolio problems that maximize the utility of terminal wealth. The Elton and Gruber work is based on the seminal scholarship of Merton (1969, 1971), Mossin (1968), and Samuelson (1969). These early works provide useful insight about the structure of optimal portfolios.

Ho, Milevsky, and Robinson (1994) develop a model to estimate the optimal portfolio allocation between a risky security and a risk-free asset. They conclude that retirement portfolios should have larger allocations of equities than suggested by conventional wisdom on portfolio allocations by age of retiree. In a more recent study, Milevsky, Ho, and Robinson (1997) extend their earlier research by simulating financial market returns and life expectancies. They use Monte Carlo simulation in their recent analysis. The simulation provided empirical support for larger equity allocations in retirement portfolios.

Pye $(1999,2000)$ provides additional examples of simulation studies in retirement and endowment fund planning and provides a useful explanation of Monte Carlo simulation as applied in retirement planning. He reports the results of simulations that examine the sustainability of withdrawal from portfolios. He also concludes that conservative withdrawal rates are sustainable over long payout periods if real portfolio returns are expected to be eight percent with a standard deviation of 18 percent.

Vora and McGinnis (2000) address optimal asset allocation for retirement portfolios as the retiree draws down the portfolio. Contrary to the conventional wisdom, they also conclude that retirement should rely heavily on equities.

Cooley, Hubbard and Waltz $(1998,1999,2001)$ employ overlapping periods of historical stock returns and corporate bond returns to investigate the sustainability of a wide set of withdrawal rates over multiple payout periods within different portfolio asset allocations. Monte Carlo simulation is applied by Cooley, Hubbard and Waltz (2003) to the sustainability of retirement portfolios. Farrell( 2001), Milevsky and Panyagometh (2001), Savage (2004), and Savage (2006) address a range of portfolio issues and problems of mutual funds using Monte Carlo simulation.

The purpose of this study is to demonstrate a defined programming method for constructing an optimal portfolio. The programming process uses the @RISK simulation model to estimate the value of the investment deflated in today's dollars. The investment considered is a retirement portfolio comprising several investment choices in Treasury bonds, Treasury bills, and equities. The value-at-risk VAR for the different scenarios considered is calculated. VAR is the lowest possible expected return given a certain probability over the course of the investment horizon.

\section{METHODOLOGY}

Historical annual returns are obtained for each of the financial assets to be considered. For this study, they include Treasury bond, Treasury bill, and value-weighted equity index. As well, the corresponding inflation rates are obtained from various Internet sources.

The simulation model is based on creating future scenarios by randomly choosing past scenarios, giving higher probability weights to more recent years. The most recent year is given a weight of one. Then the weight for 
any particular year is a "damping factor" multiplied by the weight of the following year. Further, these weights are transformed to probabilities and used in the scenario approach. Finally, the estimated future value of the investment is deflated to determine the amount in today's dollars. The model also applies value at risk VAR methods for analyzing risk by examining probabilities of failing to achieve various target portfolio values.

\section{THE SIMULATION}

For simplicity, consider a 35- year -old investor who plans to retire at age 65 . The investor plans to contribute $\$ 1,000$ at the beginning of each of the next 30 years into a retirement fund, which comprises three securities: stocks, Treasury bonds, and Treasury bills. Fixed portfolio weights are chosen for each of these securities in order to maximize expected portfolio value, calculated in present value terms.

At the same time, the investor is concerned about the downside risk involved in the process. To this end, the @Risk simulation model is employed to measure the degree risk involved for each performance scenario. Further, the model applies value-at-risk VAR methods by examining probabilities of failing to achieve various target portfolio values. For the purpose of this analysis, VAR is defined as the $5^{\text {th }}$ percentile of a distribution. It identifies the maximum expected return below which there is a five percent chance that the actual portfolio return would fall. The spreadsheet modeling is outlined as follows:

Step 1. Collect historical data.

Historical data includes 3-month treasury bills (T-bills), 10-year Treasury bonds (T-Bonds), S\&P 500 annual return with dividend reinvestment, and inflation rates. Sample period is from 1982 to 2007. The historical data are presented in Appendix 1.

Step 2. Set the initial investment weights for the three securities.

Fifteen trial investment weights are created. The sum of each trial set of weights should add to one. The trial weights are presented in Appendix 2.

Step 3. Construct the probability distribution for the historical data.

The most challenging modeling phase is to decide on a way to use historical returns and inflation factors to generate future values of these quantities. One suggestion is to use the "scenario" approach. The model will think that each historical year will be considered as a possible scenario, where each scenario specifies the returns and inflation factor for that year. Then for the future years, the model will randomly choose one of these scenarios. It is more logical and applicable to give greater likelihood for more recent years to be chosen. To implement this idea, the model uses a weight associated with each scenario. The highest weight of one will be assigned to the most recent year, 2007. Then the weight for each preceding year is a "damping factor" multiplied by the weight from next year. For example, the weight for 1999 will be a damping factor multiplied by the weight of year 2000. To change theses weights into probabilities, each weight is divided by the sum of all the weights. For this analysis, the model uses eight damping factors ranging from 0.92 to 0.99 with an increment of 0.01 . Appendix 3 represents the probability distribution for a damping factor equal to 0.99 .

Step 4. Calculate the deflation factors (deflators).

The deflation factor for year 1982 is equal to 1 divided by the inflation factor for year 1982. The deflation factor for 1983 is equal to 1 divided by the product of the inflation factor for the years 1982 and 1983, and so on. In other words, the deflator effect for year 2007 will be 1 divided by the product of all 25 inflation factors up to that year.

Step 5. Calculate the final cash value in today's dollars.

The initial investment of $\$ 1,000$ is invested using the trial investment weights for the randomly selected scenario year. The beginning cash for the second year is equal to the ending cash for the first year plus the additional $\$ 1,000$. The beginning cash grows in every year. To estimate the value of the investment at the end of the investment period in today's dollars, the final cash at the end of the 30 years is multiplied by the deflator for year 30 . Notice that this is 
similar to calculating the net present value. The only difference is that the inflation rates are not constant through the 30 years, while NPV calculations usually involve the same discount rate each year.

Step 6. Run the simulation.

The model employs the @RISK simulation program to simulate 30 scenarios, one for each year. Each scenario is randomly selected based on the probability distribution. More recent years have higher probabilities, meaning that they have a greater chance of being chosen. The model then runs 1,000 iterations for each simulation and would test 15 simulations, one for each trial investment weight. Those 15 simulations will be repeated for each damping factor.

\section{SIMULATIONS RESULTS}

The Palisade @Risk simulations results for the 15 trial investment weights are presented in Tables 1, 2, and 3. Table1 shows the mean final cash in today's dollars along with value at risk VAR for $0.92,0.93$, and 0.94 damping factors. Table 2 presents the results for $0.95,0.96$, and 0.97 damping factors. Table 3 presents the results for 0.98 , and 0.99 damping factors

Table 1: Mean of Final cash (Today's Dollars) and Value at Risk For 0.92 -0.94 Damping Factors

\begin{tabular}{|c|c|c|c|c|c|c|c|c|c|}
\hline \multirow{2}{*}{$\begin{array}{l}\text { Sim. } \\
\text { No. }\end{array}$} & \multicolumn{3}{|c|}{ Trial Invest. Weights } & \multicolumn{2}{|c|}{$\mathrm{DF}=0.92$} & \multicolumn{2}{|c|}{$\mathrm{DF}=0.93$} & \multicolumn{2}{|c|}{$\mathrm{DF}=0.94$} \\
\hline & T-Bills & T-Bonds & Stocks & Mean & VAR & Mean & VAR & Mean & VAR \\
\hline 1 & 0.05 & 0.05 & 0.9 & $\$ 80,656$ & $\$ 29,327$ & $\$ 85,758$ & $\$ 31,464$ & $\$ 89,915$ & $\$ 31,434$ \\
\hline 2 & 0.1 & 0.1 & 0.8 & $\$ 71,992$ & $\$ 29,838$ & $\$ 76,027$ & $\$ 31,724$ & $\$ 79,445$ & $\$ 31,518$ \\
\hline 3 & 0.15 & 0.15 & 0.7 & $\$ 64,303$ & $\$ 30,201$ & $\$ 67,477$ & $\$ 31,716$ & $\$ 70,260$ & $\$ 31,661$ \\
\hline 4 & 0.2 & 0.2 & 0.6 & $\$ 57,481$ & $\$ 30,418$ & $\$ 59,960$ & $\$ 31,668$ & $\$ 62,204$ & $\$ 31,901$ \\
\hline 5 & 0.25 & 0.25 & 0.5 & $\$ 51,428$ & $\$ 30,263$ & $\$ 53,349$ & $\$ 31,410$ & $\$ 55,137$ & $\$ 31,808$ \\
\hline 6 & 0.3 & 0.3 & 0.4 & $\$ 46,058$ & $\$ 29,994$ & $\$ 47,531$ & $\$ 31,150$ & $\$ 48,936$ & $\$ 31,802$ \\
\hline 7 & 0.35 & 0.35 & 0.3 & $\$ 41,292$ & $\$ 30,000$ & $\$ 42,407$ & $\$ 30,832$ & $\$ 43,494$ & $\$ 31,337$ \\
\hline 8 & 0.4 & 0.4 & 0.2 & $\$ 37,064$ & $\$ 29,472$ & $\$ 37,892$ & $\$ 30,135$ & $\$ 38,717$ & $\$ 30,841$ \\
\hline 9 & 0.45 & 0.45 & 0.1 & $\$ 33,310$ & $\$ 28,935$ & $\$ 33,909$ & $\$ 29,201$ & $\$ 34,520$ & $\$ 29,788$ \\
\hline 10 & 0.5 & 0.5 & 0 & $\$ 29,977$ & $\$ 27,346$ & $\$ 30,394$ & $\$ 27,647$ & $\$ 30,831$ & $\$ 27,823$ \\
\hline 11 & 0.3 & 0.2 & 0.5 & $\$ 50,698$ & $\$ 29,679$ & $\$ 52,577$ & $\$ 30,988$ & $\$ 54,322$ & $\$ 31,312$ \\
\hline 12 & 0.2 & 0.3 & 0.5 & $\$ 52,169$ & $\$ 30,860$ & $\$ 54,134$ & $\$ 31,839$ & $\$ 55,965$ & $\$ 32,356$ \\
\hline 13 & 0.4 & 0.2 & 0.4 & $\$ 44,774$ & $\$ 29,225$ & $\$ 46,179$ & $\$ 30,283$ & $\$ 47,516$ & $\$ 30,960$ \\
\hline 14 & 0.2 & 0.4 & 0.4 & $\$ 47,381$ & $\$ 30,900$ & $\$ 48,927$ & $\$ 32,046$ & $\$ 50,403$ & $\$ 32,782$ \\
\hline 15 & 0.5 & 0.25 & 0.25 & $\$ 37,780$ & $\$ 28,708$ & $\$ 38,682$ & $\$ 29,609$ & $\$ 39,570$ & $\$ 30,072$ \\
\hline
\end{tabular}

Table 2: Mean of Final cash (Today's Dollars) and Value at Risk For 0.95 -0.97 Damping Factors

\begin{tabular}{|c|c|c|c|c|c|c|c|c|c|}
\hline \multirow{2}{*}{$\begin{array}{l}\text { Sim. } \\
\text { No. }\end{array}$} & \multicolumn{3}{|c|}{ Trial Invest. Weights } & \multicolumn{2}{|c|}{$\mathrm{DF}=0.95$} & \multicolumn{2}{|c|}{$\mathrm{DF}=0.96$} & \multicolumn{2}{|c|}{$\mathrm{DF}=\mathbf{0 . 9 7}$} \\
\hline & T-Bills & T-Bonds & Stocks & Mean & VAR & Mean & VAR & Mean & VAR \\
\hline 1 & 0.05 & 0.05 & 0.9 & $\$ 94,254$ & $\$ 33,538$ & $\$ 99,552$ & $\$ 36,827$ & $\$ 104,688$ & 38,606 \\
\hline 2 & 0.1 & 0.1 & 0.8 & $\$ 83,035$ & $\$ 33,501$ & $\$ 87,291$ & $\$ 36,401$ & $\$ 91,421$ & 38,598 \\
\hline 3 & 0.15 & 0.15 & 0.7 & $\$ 73,208$ & $\$ 33,269$ & $\$ 76,609$ & $\$ 36,154$ & $\$ 79,909$ & 37,635 \\
\hline 4 & 0.2 & 0.2 & 0.6 & $\$ 64,602$ & $\$ 32,861$ & $\$ 67,300$ & $\$ 35,452$ & $\$ 69,918$ & 36,837 \\
\hline 5 & 0.25 & 0.25 & 0.5 & $\$ 57,065$ & $\$ 32,602$ & $\$ 59,188$ & $\$ 34,823$ & $\$ 61,247$ & 36,182 \\
\hline 6 & 0.3 & 0.3 & 0.4 & $\$ 50,464$ & $\$ 32,216$ & $\$ 52,117$ & $\$ 33,939$ & $\$ 53,720$ & 35,373 \\
\hline 7 & 0.35 & 0.35 & 0.3 & $\$ 44,683$ & $\$ 31,462$ & $\$ 45,951$ & $\$ 32,779$ & $\$ 47,183$ & 34,288 \\
\hline 8 & 0.4 & 0.4 & 0.2 & $\$ 39,618$ & $\$ 30,899$ & $\$ 40,574$ & $\$ 31,843$ & $\$ 41,505$ & 33,175 \\
\hline 9 & 0.45 & 0.45 & 0.1 & $\$ 35,181$ & $\$ 30,016$ & $\$ 35,881$ & $\$ 30,603$ & $\$ 36,571$ & 31,705 \\
\hline 10 & 0.5 & 0.5 & 0 & $\$ 31,291$ & $\$ 28,278$ & $\$ 31,784$ & $\$ 28,661$ & $\$ 32,280$ & 29,175 \\
\hline 11 & 0.3 & 0.2 & 0.5 & $\$ 56,204$ & $\$ 32,258$ & $\$ 58,278$ & $\$ 34,361$ & $\$ 60,286$ & 35,601 \\
\hline 12 & 0.2 & 0.3 & 0.5 & $\$ 57,940$ & $\$ 33,132$ & $\$ 60,114$ & $\$ 35,292$ & $\$ 62,225$ & 36,775 \\
\hline 13 & 0.4 & 0.2 & 0.4 & $\$ 48,969$ & $\$ 31,381$ & $\$ 50,543$ & $\$ 32,976$ & $\$ 52,065$ & 34,202 \\
\hline 14 & 0.2 & 0.4 & 0.4 & $\$ 52,008$ & $\$ 33,231$ & $\$ 53,744$ & $\$ 35,092$ & $\$ 55,431$ & 36,544 \\
\hline 15 & 0.5 & 0.25 & 0.25 & $\$ 40,541$ & $\$ 30,116$ & $\$ 41,575$ & $\$ 31,160$ & $\$ 42,577$ & 32,556 \\
\hline
\end{tabular}


Table 3: Mean of Final cash (Today's Dollars) and Value at Risk For 0.98 -0.99 Damping Factors

\begin{tabular}{|c|c|c|c|c|c|c|c|}
\hline \multirow{2}{*}{$\begin{array}{l}\text { Sim. } \\
\text { No. }\end{array}$} & \multicolumn{3}{|c|}{ Trial Invest. Weights } & \multicolumn{2}{|c|}{$\mathrm{DF}=0.98$} & \multicolumn{2}{|c|}{$\mathrm{DF}=0.99$} \\
\hline & T-Bills & T-Bonds & Stocks & Mean & VAR & Mean & VAR \\
\hline 1 & 0.05 & 0.05 & 0.9 & $\$ 110,903$ & $\$ 41,537$ & $\$ 117,474$ & $\$ 44,229$ \\
\hline 2 & 0.1 & 0.1 & 0.8 & $\$ 96,374$ & $\$ 41,158$ & $\$ 101,586$ & $\$ 43,159$ \\
\hline 3 & 0.15 & 0.15 & 0.7 & $\$ 83,837$ & $\$ 40,205$ & $\$ 87,942$ & $\$ 41,931$ \\
\hline 4 & 0.2 & 0.2 & 0.6 & $\$ 73,015$ & $\$ 39,581$ & $\$ 76,222$ & $\$ 40,779$ \\
\hline 5 & 0.25 & 0.25 & 0.5 & $\$ 63,670$ & $\$ 38,406$ & $\$ 66,150$ & $\$ 39,487$ \\
\hline 6 & 0.3 & 0.3 & 0.4 & $\$ 55,595$ & $\$ 36,861$ & $\$ 57,493$ & $\$ 38,107$ \\
\hline 7 & 0.35 & 0.35 & 0.3 & $\$ 48,615$ & $\$ 35,198$ & $\$ 50,047$ & $\$ 36,430$ \\
\hline 8 & 0.4 & 0.4 & 0.2 & $\$ 42,578$ & $\$ 33,690$ & $\$ 43,640$ & $\$ 34,822$ \\
\hline 9 & 0.45 & 0.45 & 0.1 & $\$ 37,353$ & $\$ 31,910$ & $\$ 38,124$ & $\$ 32,528$ \\
\hline 10 & 0.5 & 0.5 & 0 & $\$ 32,828$ & $\$ 29,374$ & $\$ 33,370$ & $\$ 29,725$ \\
\hline 11 & 0.3 & 0.2 & 0.5 & $\$ 62,655$ & $\$ 37,786$ & $\$ 65,076$ & $\$ 38,802$ \\
\hline 12 & 0.2 & 0.3 & 0.5 & $\$ 64,702$ & $\$ 39,038$ & $\$ 67,243$ & $\$ 40,136$ \\
\hline 13 & 0.4 & 0.2 & 0.4 & $\$ 53,855$ & $\$ 35,784$ & $\$ 55,660$ & $\$ 36,818$ \\
\hline 14 & 0.2 & 0.4 & 0.4 & $\$ 57,396$ & $\$ 38,095$ & $\$ 59,391$ & $\$ 39,298$ \\
\hline 15 & 0.5 & 0.25 & 0.25 & $\$ 43,743$ & $\$ 33,301$ & $\$ 44,900$ & $\$ 34,062$ \\
\hline
\end{tabular}

\section{DISCUSSION OF THE SIMULATIONS RESULTS}

Different damping factors provide different probability distribution for scenario selections. Therefore, different simulation results will occur. The results show that the first simulation, which invests heavily in stocks, is easily the winner when a damping factor of 0.99 is used. Its mean final cash is $\$ 117,474$ in today's dollars value. Its VAR value is $\$ 44,229$, which means that there is $5 \%$ chance of ending up with no more than this amount. This is the value investors always worry about. To invest $\$ 1,000$ yearly for 30 years and end up with a value very close to the initial investment is something to worry about for any investor. There are always various amounts of risk associated with any investment. It is also important for any investor to know, in advance, the expected return, along with the associated risk is for any investment.

Figure 1: Final Cash (Today's dollars) Histogram Distribution for Simulation \#1 (Damping Factor DF=0.99)

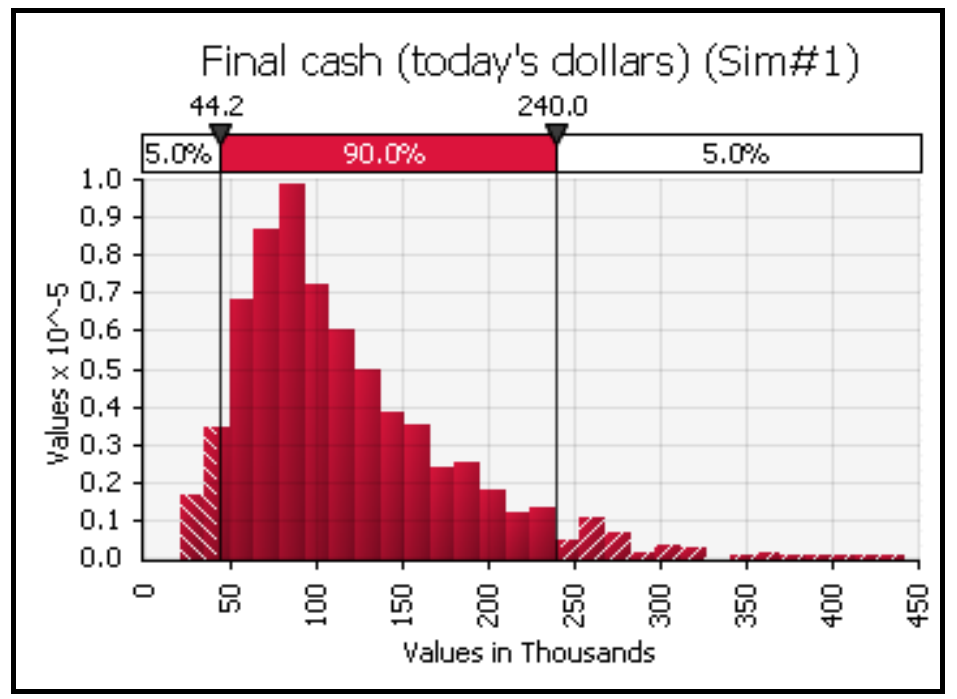

Palisade @Risk simulation also provides more summary statistics and graphs for a specific simulation output. In our discussion, the present mean final cash value is produced by simulation results that warrant thorough analysis. The behavior and the histogram distribution of the mean final cash value from simulation 1(0.05 invested 
in T-bills, 0.05 invested in T-Bonds, and 0.90 invested in stocks when a damping factor of 0.99 is used) is shown in figure 1. Appendix 4 represents the histogram distributions of the final cash for simulation 1 using different damping factors.

As displayed in Figure 1 and in Appendix 4, the histogram of the final cash is a positively skewed distribution and indicates a lot of variability. Figure 1 also shows that the $95^{\text {th }}$ percentile is over $\$ 228,000$. By analyzing all the simulation results for simulation \# 1 using different damping factors, we can conclude that investing heavily in stocks and using a damping factor of 0.99 will provide the best final cash (today's dollars) and it also grants the best value at risk VAR. Figure 2 displays the mean final cash and the value at risk VAR versus the fraction invested in stocks when a damping factor of 0.99 is used.

Figure 2: Mean Final Cash and VAR versus the Fraction Invested in Stocks when a Damping Factor of 0.99 is used

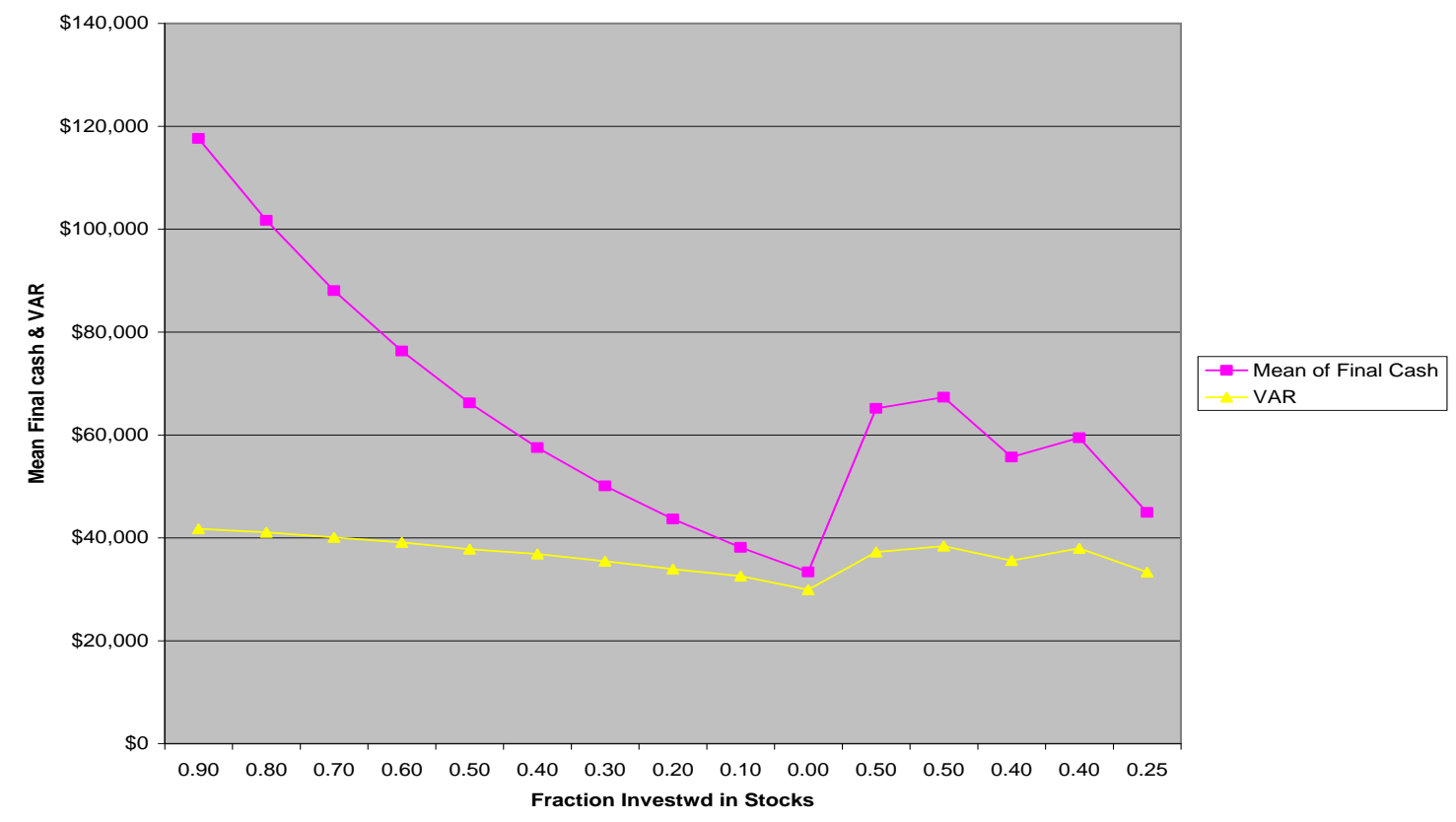

Figure 2 shows that as the fraction invested in stocks decreases, the mean final cash also decreases deeply and value at risk VAR decreases mildly. If the investor decides not to invest in stocks, the mean final cash (today's dollars) is getting very close to its value at risk VAR. For example, simulation number 10 suggests 0.50 invested in T-bills, 0.50 invested in T-bonds and none invested in stocks. When a damping factor of 0.99 is used, the mean final cash (today's dollars) is estimated to be $\$ 33,370$ and the VAR is estimated to be $\$ 29,725$. Therefore, the investor will decide not to implement this strategy.

\section{CONCLUSION}

A variety of industries have used the Monte Carlo methods. In 1940, Scientists at Los Alamos, N.M. used its principles when they worked on the atomic bomb. Another application to the Monte Carlo simulation is used by urban planners to predict traffic patterns. Today, financial planners are using it to plan for retirement.

One of the primary benefits of using probability simulation in a spreadsheet model is the ability to alter the input parameters and re-run the simulation. This will help financial planners determine the effect of changes to the input parameters on the long-term simulation results. This interactive modeling can be used to create more effective models that have a greater chance of achieving a particular goal. In our example presented in this study, any changes in the retirement date or in the yearly contribution amount, or some combination of each input parameter, will change the output results. 
Because this approach has its limitations, these models are only as good as their assumptions. Using these models doesn't eliminate uncertainty. By recognizing uncertainty, however, @RISK Monte Carlo simulation is an improved and more sophisticated form of advice as compared to traditional plans. As an added complication, it's clear that the popular approach of basing future expectations solely on what has happened in the past isn't reliable. There is no guarantee that a mutual fund that outperformed the market in one period will ever do so again. Similarly, there is no guarantee that the historical performance of any given asset will be repeated in the future.

Some people may believe that the Monte Carlo simulation is more similar to gambling than to financial planning - it is not. Stanislaw Ulam, the mathematician who discovered that you could predict a series of probable outcomes, was actually playing endless games of Solitaire when he realized the possibilities of simulation. Being able to predict what is going to happen in Solitaire-not the next card you will turn over in a game, but how a particular game will turn out based on what has happened with dozens of card combinations-is the foundation of being able to project probable financial outcomes, or traffic patterns, or telephone usage, or any other event driven by numerical information.

Using @RISK simulation by Palisade in spreadsheets helps financial planners anticipate the probability of meeting specific financial goals at certain times in the future. @RISK uses advanced Monte Carlo simulation techniques to analyze risk in any spreadsheet model. This is accomplished by generating thousands of possible scenarios the retiree's investments might take during the years until he or she is ready to retire. Analysts can find out not only what could happen, but how likely it is to happen. Fortunately, these scenarios can be used to answer important questions by the investor, such as:

- What is the chance I will meet my retirement goals?

- What is the reasonable downside to the investment strategy I am using?

Appendix 1: Historical Data From 1982-2007

\begin{tabular}{|c|c|c|c|c|}
\hline Year & $\begin{array}{c}\text { 3-months } \\
\text { T-Bills }\end{array}$ & $\begin{array}{l}\text { 10-years } \\
\text { T-Bonds }\end{array}$ & $\begin{array}{c}\text { S\&P } \\
\text { Stocks }\end{array}$ & $\begin{array}{c}\text { Inflation } \\
\text { Rate }\end{array}$ \\
\hline 1982 & 0.1110 & 0.1300 & 0.2478 & 0.0616 \\
\hline 1983 & 0.0894 & 0.1111 & 0.2097 & 0.0322 \\
\hline 1984 & 0.0990 & 0.1244 & 0.0697 & 0.0430 \\
\hline 1985 & 0.0773 & 0.1062 & 0.2852 & 0.0355 \\
\hline 1986 & 0.0616 & 0.0768 & 0.1870 & 0.0191 \\
\hline 1987 & 0.0596 & 0.0838 & 0.0977 & 0.0366 \\
\hline 1988 & 0.0688 & 0.0885 & 0.1593 & 0.0408 \\
\hline 1989 & 0.0839 & 0.0850 & 0.2853 & 0.0483 \\
\hline 1990 & 0.0774 & 0.0855 & -0.0160 & 0.0539 \\
\hline 1991 & 0.0554 & 0.0786 & 0.2801 & 0.0425 \\
\hline 1992 & 0.0352 & 0.0701 & 0.0762 & 0.0303 \\
\hline 1993 & 0.0307 & 0.0587 & 0.0980 & 0.0296 \\
\hline 1994 & 0.0437 & 0.0708 & 0.0182 & 0.0261 \\
\hline 1995 & 0.0566 & 0.0658 & 0.3245 & 0.0281 \\
\hline 1996 & 0.0515 & 0.0644 & 0.2138 & 0.0293 \\
\hline 1997 & 0.0520 & 0.0635 & 0.3030 & 0.0234 \\
\hline 1998 & 0.0491 & 0.0526 & 0.2763 & 0.0155 \\
\hline 1999 & 0.0478 & 0.0564 & 0.2003 & 0.0219 \\
\hline 2000 & 0.0600 & 0.0603 & -0.0818 & 0.0338 \\
\hline 2001 & 0.0347 & 0.0502 & -0.1076 & 0.0283 \\
\hline 2002 & 0.0163 & 0.0461 & -0.2274 & 0.0159 \\
\hline 2003 & 0.0103 & 0.0402 & 0.2606 & 0.0227 \\
\hline 2004 & 0.0140 & 0.0427 & 0.1062 & 0.0268 \\
\hline 2005 & 0.0321 & 0.0429 & 0.0509 & 0.0339 \\
\hline 2006 & 0.0485 & 0.0479 & 0.1490 & 0.0324 \\
\hline 2007 & 0.0447 & 0.0463 & 0.0578 & 0.0285 \\
\hline
\end{tabular}


Appendix 2: Trial Investment Weights

\begin{tabular}{|c|c|c|c|}
\hline & \multicolumn{2}{|c|}{ Fraction Invested in } \\
\hline Sim. \# & T-Bills & T-Bonds & 0.90 \\
\hline 1 & 0.05 & 0.05 & 0.80 \\
\hline 2 & 0.10 & 0.10 & 0.70 \\
\hline 3 & 0.15 & 0.15 & 0.60 \\
\hline 4 & 0.20 & 0.20 & 0.50 \\
\hline 5 & 0.25 & 0.25 & 0.40 \\
\hline 6 & 0.30 & 0.30 & 0.30 \\
\hline 7 & 0.35 & 0.35 & 0.20 \\
\hline 8 & 0.40 & 0.40 & 0.10 \\
\hline 10 & 0.45 & 0.45 & 0.00 \\
\hline 11 & 0.50 & 0.50 & 0.50 \\
\hline 12 & 0.30 & 0.20 & 0.50 \\
\hline 13 & 0.20 & 0.30 & 0.40 \\
\hline 15 & 0.40 & 0.20 & 0.40 \\
\hline
\end{tabular}

Appendix 3: Probability Distributions for Damping Factor DF=0.99

\begin{tabular}{|c|c|c|}
\hline Year & Prob. Wts & Probability \\
\hline 1982 & 0.7778 & 0.0338 \\
\hline 1983 & 0.7857 & 0.0342 \\
\hline 1984 & 0.7936 & 0.0345 \\
\hline 1985 & 0.8016 & 0.0349 \\
\hline 1986 & 0.8097 & 0.0352 \\
\hline 1987 & 0.8179 & 0.0356 \\
\hline 1988 & 0.8262 & 0.0359 \\
\hline 1989 & 0.8345 & 0.0363 \\
\hline 1990 & 0.8429 & 0.0367 \\
\hline 1991 & 0.8515 & 0.0370 \\
\hline 1992 & 0.8601 & 0.0374 \\
\hline 1993 & 0.8687 & 0.0378 \\
\hline 1994 & 0.8775 & 0.0382 \\
\hline 1995 & 0.8864 & 0.0385 \\
\hline 1996 & 0.8953 & 0.0389 \\
\hline 1997 & 0.9044 & 0.0393 \\
\hline 1998 & 0.9135 & 0.0397 \\
\hline 1999 & 0.9227 & 0.0401 \\
\hline 2000 & 0.9321 & 0.0405 \\
\hline 2001 & 0.9415 & 0.0409 \\
\hline 2002 & 0.9510 & 0.0414 \\
\hline 2003 & 0.9606 & 0.0418 \\
\hline 2004 & 0.9703 & 0.0422 \\
\hline 2005 & 0.9801 & 0.0426 \\
\hline 2006 & 0.9900 & 0.0431 \\
\hline 2007 & 1.0000 & 0.0435 \\
\hline Sum & 22.9957 & 1.0000 \\
\hline
\end{tabular}


Appendix 4: Final Cash (Today's dollars) Histogram Distribution for Simulation \#1, (Damping Factor DF=0.92-0.99)

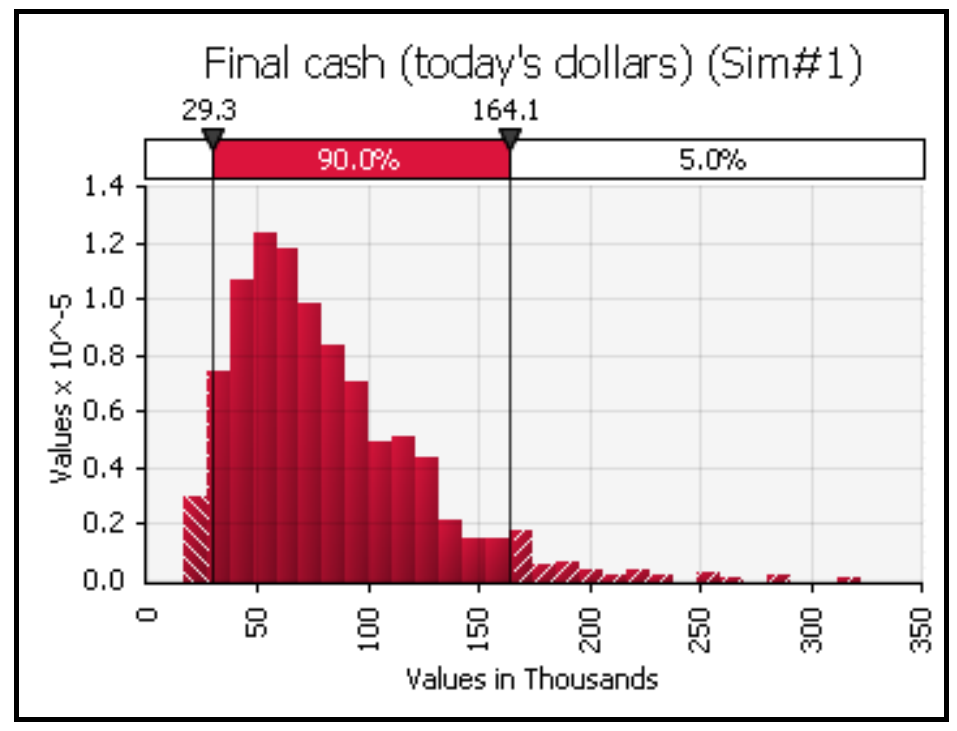

$\mathrm{DF}=0.92$

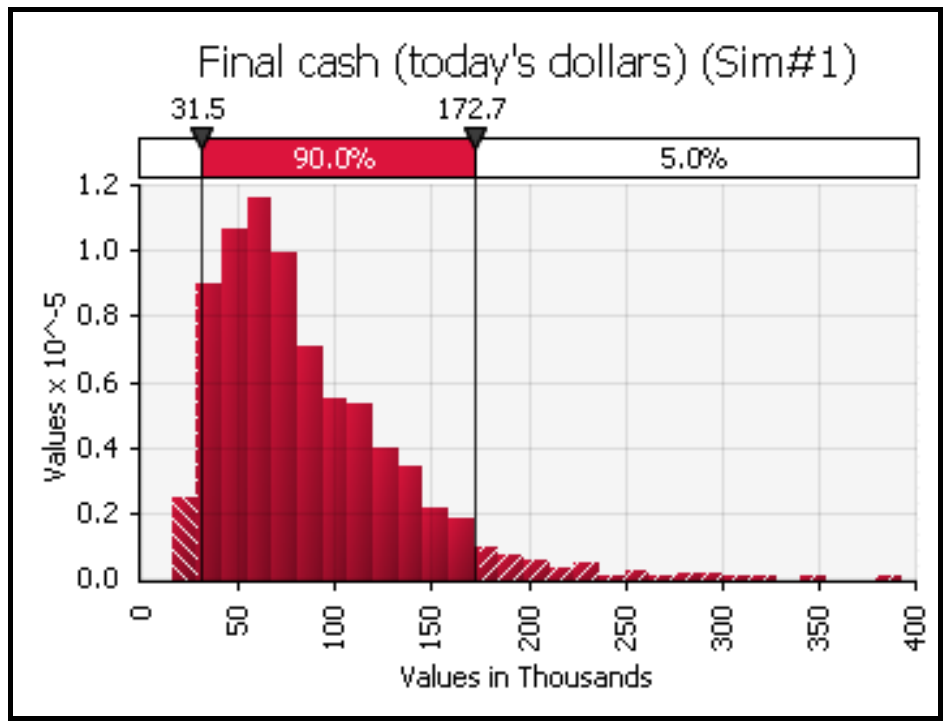

$\mathrm{DF}=0.93$ 


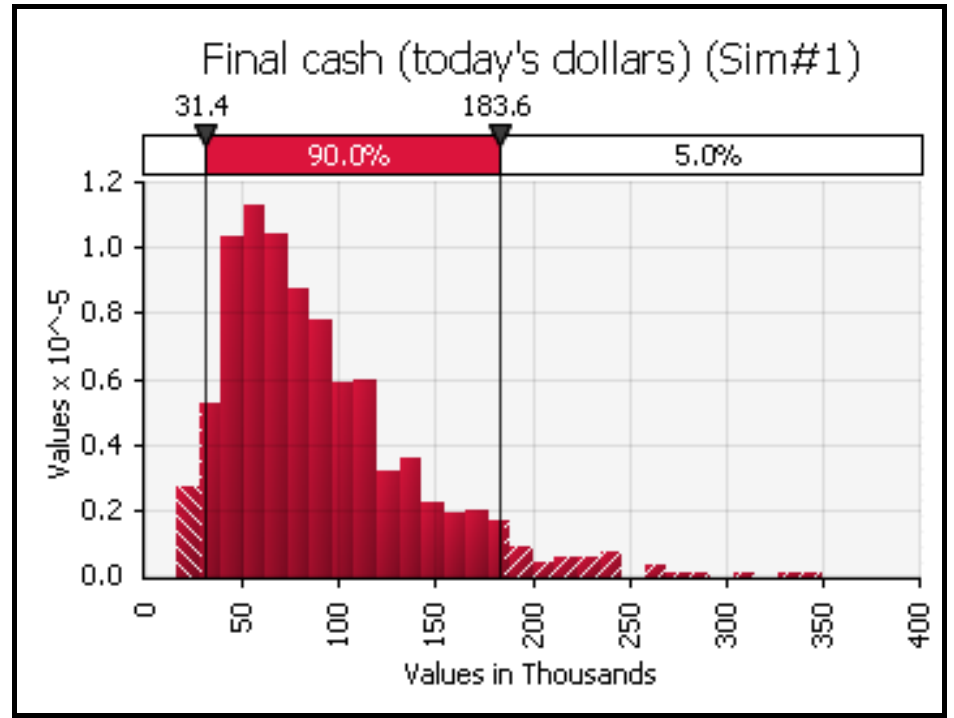

$\mathrm{DF}=0.94$

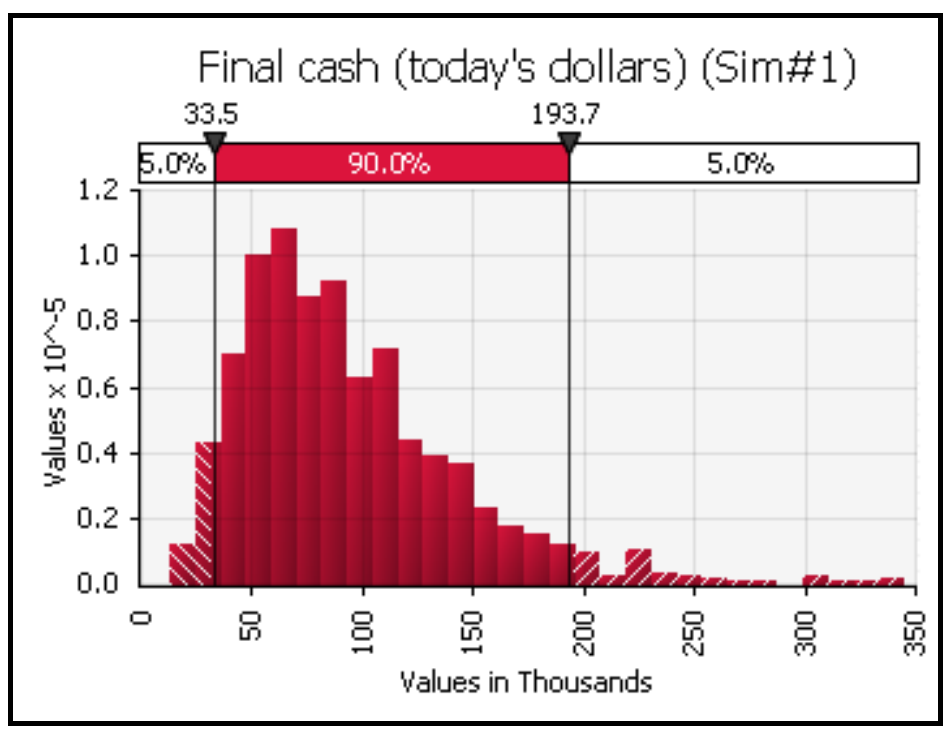

$\mathrm{DF}=0.95$ 


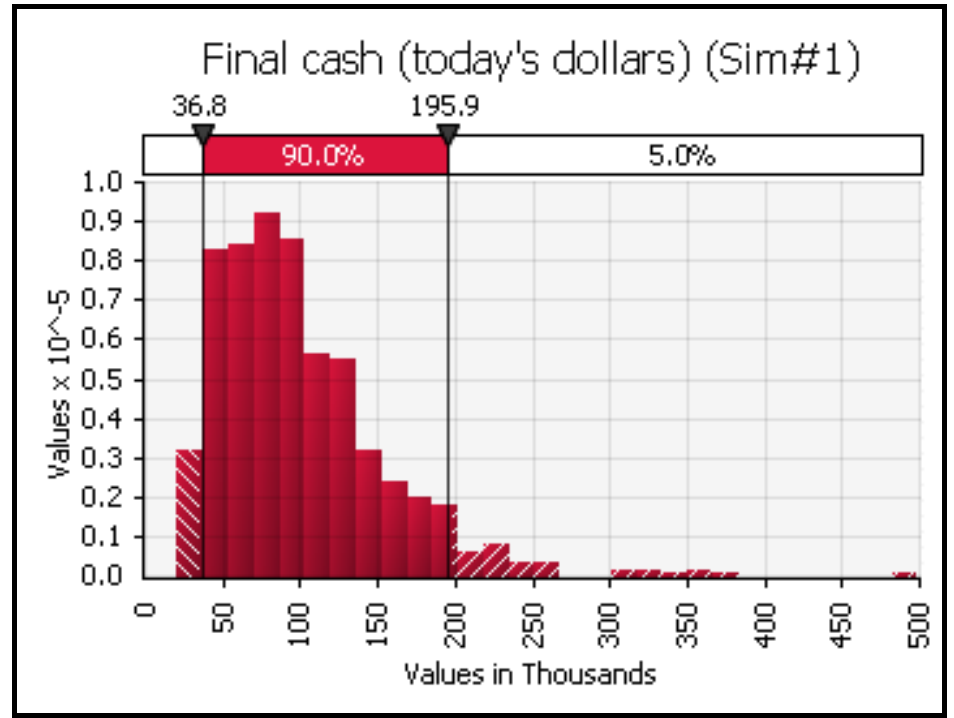

$\mathrm{DF}=0.96$

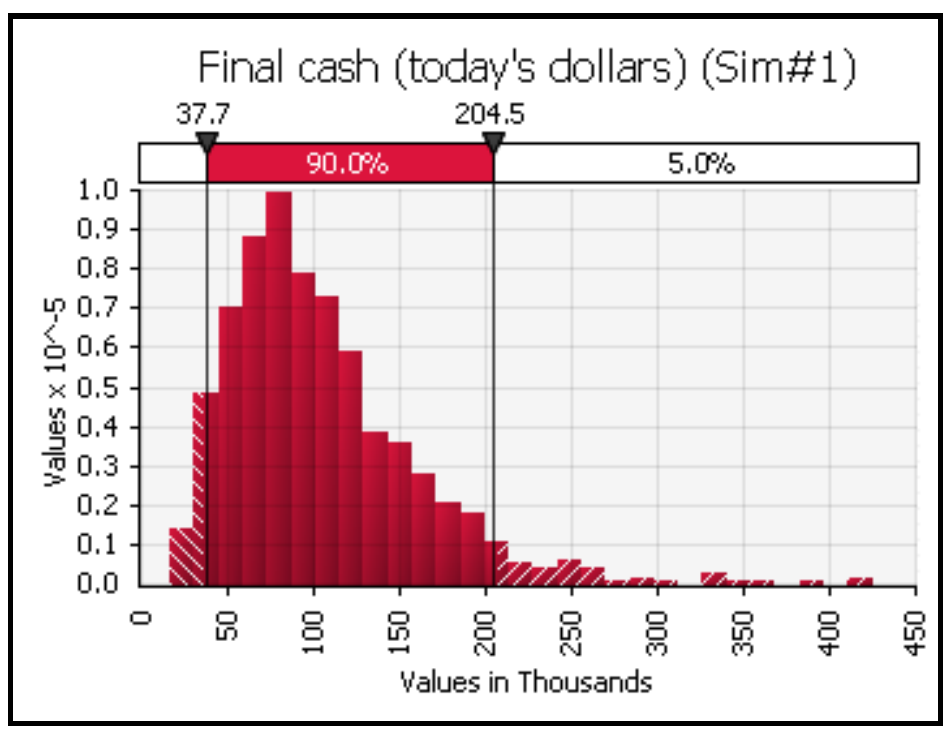

$\mathrm{DF}=0.97$ 


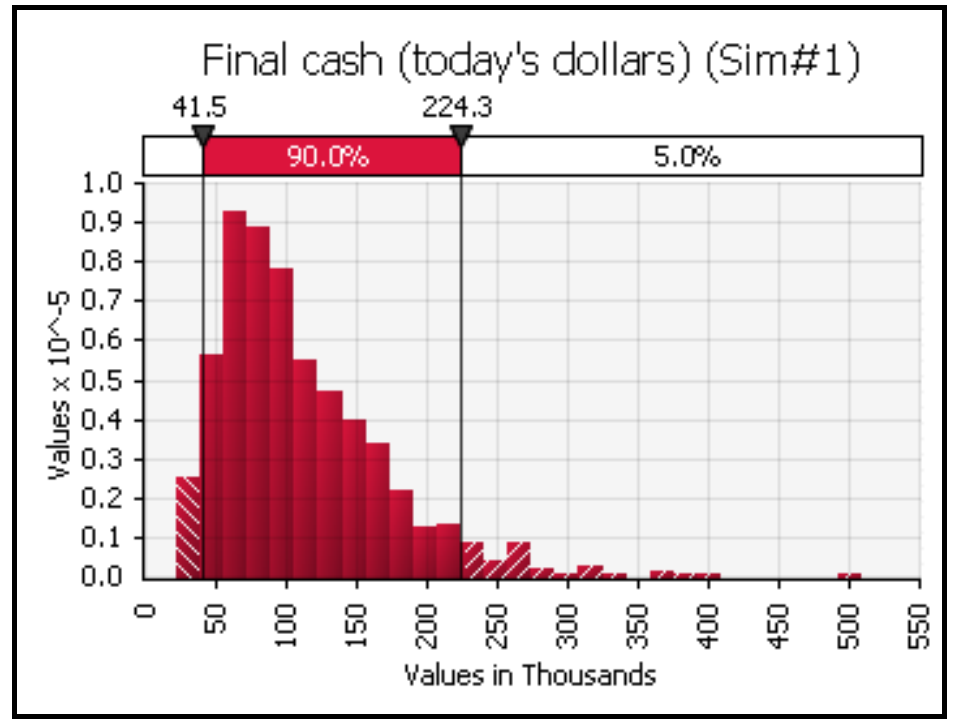

$\mathrm{DF}=0.98$

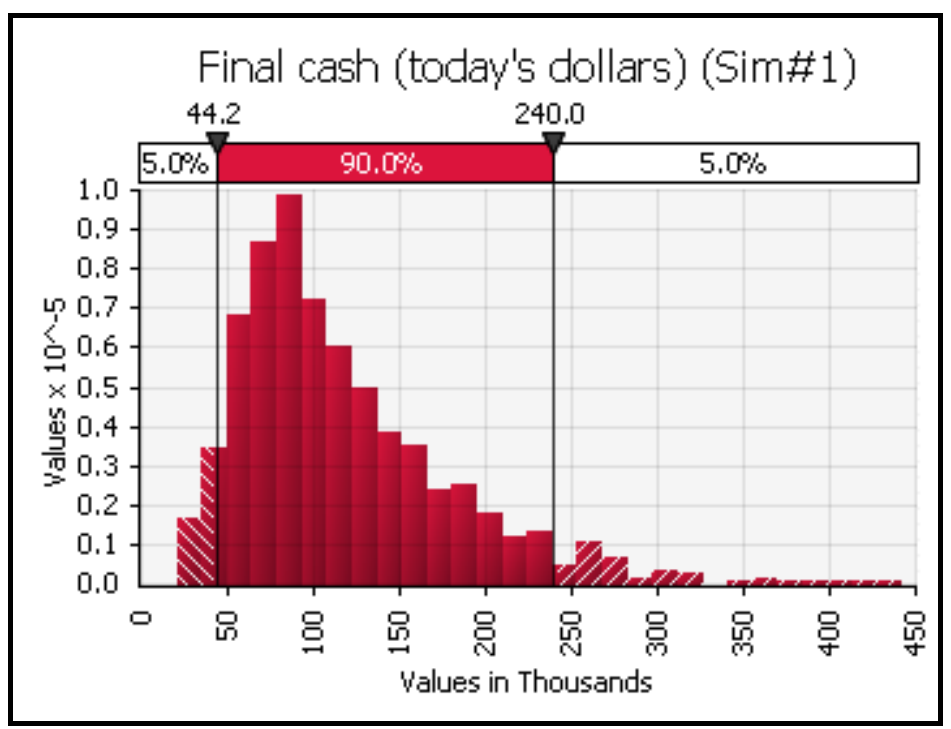

$\mathrm{DF}=0.99$

\section{AUTHOR INFORMATION}

Raida Abuizam is an Assistant Professor of Operations Management in the Department of Finance and Economics at Purdue University Calumet, Hammond Indiana, USA. She can be reached at abuizam@ @alumet.purdue.ed

\section{REFERENCES}

1. Cooly, P.L., Hubbard,C M., and Walz, D. T. (1998)," Retirement spending: Choosing a sustainable withdrawal rate that is sustainable," Journal of the American Associations of Individual Investors, Vol.20, pp 16-21. 
2. Cooly, P.L., Hubbard,C M., and Walz, D. T. (1999)," Sustainable withdrawal rates from your retirement portfolio," Financial Consulting and Planning, Vol.10, pp 39-47.

3. Cooly, P.L., Hubbard,C M., and Walz, D. T. (2001)," Withdrawing money from your retirement portfolio without going broke," Journal of Retirement Planning, Vol.4, pp 35-41.

4. Cooly, P.L., Hubbard,C M., and Walz, D. T. (2003),” A comparative analysis of retirement portfolio success rates: Simulation versus overlapping," Financial Services Review, Vol.12, pp 115-128.

5. Elton, E., Gruber, J.M., and Brown, J. (2003), Modern Portfolio Theory and Investment, $6^{\text {th }}$ edition, Irwin

6. Farrel, C. (2000)," A better way to size up your nest egg: Monte Carlo models simulate all kinds of scenarios," Businessweek Outline, pp 22

7. Ho, K., Milevsky, M. A., and Robinson, C. (1994), "Asset allocation, life expectancy, and shortfall," Financial Services Review, Vol.3, pp 109-126.

8. Levine, E. M., (2005)," Monte Carlo simulation: Smart bet for baby boomers' retirement plans," CPA Journal, Vol. 75, pp 12-13.

9. Milevsky, M. A., Ho, K. and Robinson, C. (1997), “Asset allocation via the conditional first exit time or how to avoid outliving your money," Review of Quantitative Finance and Accounting, Vol.9, pp 53-70.

10. Milevsky, M. A., and Panyagometh, K. (2001), "Variable annuities versus mutual funds: A Monte Carlo analysis of the options," Financial Services Review, Vol.10, pp 145-151.

11. Mossin, J. (1968)," Optimal Multi-period portfolio policies," Journal of Business, Vol. 41, pp 215-229.

12. Pye, G. B. (1999), "Sustainable real spending from pensions and investments," Journal of Financial Planning, Vol. 12, pp 80-91.

13. Pye, G. B. (2000), "Sustainable investment withdrawals," Journal of Portfolio Management, Vol. 26, pp 73-83

14. Samuelson, P. (1969)," Lifetime portfolio selection dynamic stochastic programming," Review of Economics and Statistics, Vol. 50, PP 239-246

15. Savage, T. (2004)," Monte Carlo modeling yields magic number for retirement," Available at: http://www.analycorp.com/suntimes_7-8-04.html

16. Savage, T. (2006)," Funds roll the dice," TheStreet.com Contributor, Available at: http://www.thestreet.com/funds/mutualfundmonday/10319388.html

17. Schleef, H. and Eisinger, R. M.( 2007)," Hitting or missing the retirement target: Comparing contribution and asset allocation schemes of simulated portfolios," Financial Services Review, Vol.16, pp 229-243.

18. Vora, P. P., and McGinnis, J. D. (2000)," The asset allocation decision in retirement: Lessons from dollarcost averaging," Financial Services Review, Vol.9, pp 47-63.

19. Winston, W., and Albright, S. C. (2001), Practical Management Science, second edition, Duxbury 
NOTES 